\title{
Inhibitory Effect of EUTHYMOL Original Toothpaste on VSC-producing Oral Bacteria
}

\author{
Hyojin Kim ${ }^{1}$, Wonkyung Choi ${ }^{2}$, Wonkyung Lee ${ }^{2}$, Wonchan $\mathrm{Kim}^{2}$, Kyounghee $\mathrm{Oh}^{1}$, Wonho $\mathrm{Ha}^{3}$ \\ ${ }^{1}$ Preventive Dentistry Research Team, LG H\&H Research Center, Seoul Korea, ${ }^{2}$ Deodorizing Tech Project, LG H\&H \\ Research Center, Daejeon, Korea, ${ }^{3}$ Oral Health R\&D Division, LG H\&H Research Center, Seoul, Korea
}

Objective: Oral malodor (bad breath) is generally the result of microbial metabolism, and volatile sulfur compounds (VSC) producing bacteria are mainly present in biofilm of tongue dorsum, are the main cause of halitosis. Many studies have revealed that these bacteria are also associated with periodontal disease. We developed a flavoring agent by combining ingredients that identified to have oral antibacterial properties, and applied to EUTHYMOL original toothpaste. In this study, we examine the effect of suppressing oral bacteria and reducing VSC production of the toothpaste.

Methods: 1) Oral bacteria inhibitory test: $P$. gingivalis, F. periodonticum are cultured in BHI medium at anaerobic incubation system. The toothpaste samples were treated for $24 \mathrm{~h}$ on bacterium culture condition, VSC was detected by Oral Chroma. 2) Salivary incubation test: Saliva suspension from healthy adults was incubated anaerobically with amino acids (cysteine and methionine) and toothpaste samples for 4h, and VSC was measured by Oral Chroma.

Results: As a result of the VSC inhibition test of oral bacteria, $82.6 \%$ of $P$. gingivalis inhibition rate was revealed compared to the non-treated group, and 1.41-fold difference compared to the unscented toothpaste treatment group. Also, 49.2\% of F. periodonticum inhibition rate was showed compared to the non-treated group. In saliva incubation test, the VSC inhibition rate was $58.9 \%$ compared to the non-treated group, and 1.45-fold difference compared to the unscented toothpaste treatment group.

Conclusion: We revealed the anti-microbial effect of EUTHYMOL original toothpaste on halitosis-inducing oral bacteria. Through this study, the effect of suppressing bad breath through VSC inhibition in oral cavity can be expected.

Keywords: halitosis, VSC, bacteria, saliva, EUTHYMOL

Copyright (C) 2021. Korean Academy of Preventive Dentistry. All rights reserved.

This is an Open Access article distributed under the terms of the Creative Commons Attribution Non-Commercial License (http://creativecommons.org/licenses/ by-nc/4.0) which permits unrestricted non-commercial use, distribution, and reproduction in any medium, provided the original work is properly cited. 